\title{
JOB HUNTING BY THROUGH THE INTERNET: THE EXPERIENCES OF SOME GRADUATES OF NIGERIAN TERTIARY INSTITUTIONS
}

\author{
E. N. NWAGBARA \\ (Received 14, May 2008; Revision Accepted 19, May 2009)
}

\begin{abstract}
Each year, thousands of graduates are turned into the labour market from over fifty tertiary institutions in Nigeria in search of jobs. In addition to the traditional methods of job-hunting, most of these graduates are increasingly using the Internet as a veritable source of job opportunities. However, jobhunting through the Internet is fraught with limitations that form a stumbling block to job-seekers especially those that lack the necessary search skills. Unfortunately, most university graduates do not possess these skills. This study was motivated by the need for Nigerian graduates to improve their job-search skills. The general aim of the study was to examine the problems and prospects of using the Internet as a tool for jobhunting in Nigeria. A sample size of 500 was drawn from selected graduates undergoing the National Youth Service Corps (NYSC) in Cross River State. The findings show a high level of use of the Internet for jobhunting. Furthermore, the study reveals that these graduates encounter problems and frustrations in surfing the Internet for jobs. Based on the findings, the author recommends that Internet infrastructure in Nigeria be upgraded by the operators; graduates sharpen their search skills and that government and corporate organizations in Nigeria create jobs and place their adverts on the Internet for accessibility to the jobhunters.
\end{abstract}

KEY WORDS: Internet, job-hunting, search skill, graduates, poverty.

\section{INTRODUCTION}

The description of Nigeria as a paradox by some commentators can hardly be disputed (Duru, 1999). In spite of her rich endowment with natural and human resources, majority of Nigerians wallow in poverty. The United Nations Development Programme (UNDP, 2004) Human Development Report shows that majority of Nigerians still live below $\$ 1$ per day.

With all her huge foreign revenue from crude oil, Nigeria still lacks industries to provide decent job opportunities for her teeming population. Thus, the high rate of unemployment among the graduates from Nigerian universities has been blamed on a quantitative expansion of the educational system without due regard to the economy.

Education, apart from providing the society, ought to aim at nation building as well as promotion of the economic self reliance and self sufficiency for graduates (Borishade, 2001). This has not been attained. The result is a burgeoning army of underemployed and unemployed ablebodied segment of the population.

The poverty reduction programmes initiated by successive political leaderships in Nigeria to cushion the effect of unemployment have not impacted positively on the lives of these graduates some of whom are forced to engage in anti-social behaviour such as prostitution, drug trafficking, robbery and fraudulent practices to make ends meets.

However, many graduates in Nigeria are living up to the challenges of joblessness by searching frantically through the use of multimedia. Internet is one of these commonly used media. From the over fifty tertiary institutions in the country graduates are churned out annually into the over-saturated labour market in search of jobs. Today, this complex problem of youth unemployment is one of the major causes of social upheavals in the country including Niger Delta crises. Indeed, violent crime, poverty, insecurity

E. N. Nwagbara, Department of Sociology, University of Calabar, P.M.B 1115, Calabar, Cross River State, Nigeria 
and youth restiveness characterize social live in the society (Nwagbara, 2007).

\section{LITERATURE REVIEW}

As in many other parts of the world, use of the Internet continue to grow rapidly in Nigeria. Apart from the common usage as means of communication via e-mail, variety of information is accessed by users of the Internet through the use of 'search engines' such as Google and Yahoo. As Marshall (1998) observed,

[the Internet] allows instantaneous access to an expanding number of individual Web sites offering information about practically anything and everything - including the contents of daily newspapers, the price of goods in local shopping malls, library holdings, commodity prices, sports news and gossip, eroticism, and so-called chatrooms (by means of which people can communicate with each other on-line about their interests, hobbies, and opinions).

While some Nigerians use the Internet for advanced fee fraud and other negative purposes that have earned Nigeria a bad international image, graduates of tertiary institutions increasingly use it for job hunting. The social phenomenon of job search has long been subjected to investigation in developed countries (Richard, 1999; Robert, 1983). In his contribution, Robert (1983) highlighted the difference between successful job hunting and unsuccessful job hunting noting that this does not depend much on the steps taken but how well one executes each step. For instance, the question of how well a graduate makes himself or herself marketable should be uppermost in the mind of the job hunter before actual hunting.

According to Richard (1999) there are three basic or fundamental truths that a graduate should know about job-search. These are as follows:

(1) There are always jobs out there waiting to be filled.

(2) Whether you can find this job or not, depends on what job-search method you are using.

(3) If you are job-hunting and not coming up with concrete result, you need to change the method you are using.

A detailed analysis of the mentioned truths will enable the graduate see and believe in his/her ability to secure a job. In the case of the first fundamental truth, everyday lots of jobs are created in developed and developing countries alike. However in Nigeria data about newly created jobs are not documented. Apart from job-creation people are promoted and as such they leave vacancies to be filled. Again, some retire, resign or may migrate to other places or become injured, sick or even die. So for all these reasons, the Development Policy Centre (1999) observed that there are always jobs out there. The second fundamental truth, a graduate who has been using wrong job search strategy can hardly secure a desired job. Consequently, everything depends on the method job seekers are using to find these jobs that are out there. (National Directorate of Employment, 2000; 2001). The third fundamental truth clearly advocates for a change in the search method being used. This will enable the graduate know if he or she is using the right method or not.

On the issue of job hunting strategies, Nelson (1999) outlined ten methods of job-search available and widely used by graduates when they go job-hunting. Steven and Michelle (1992) have tested the success or failure of these methods in their study. The following five are some of the jobsearch strategies with the worst success rate.

(1) Using the Internet, the success late for this search method is $1 \%$ for every 100 jobhunting using the Internet as their search method; exactly one will get the job. Therefore 99 will not get the job using only this method to search for job.

(2) Mailing out resumes to employer at random. This search method has a $7 \%$ success rate. That is, for every 100 graduates that use this method only, 93 will not get this job.

(3) Answering local newspaper adverts. This search method has a $5-24 \%$ success rate. So $76-95 \%$ will not get a job using only this search method. The fluctuation is due to the level of salary being sought. The higher salary being sought the fewer jobhunters who are able to find a job using this search method only.

(4) Answering adverts in professional or trade journals. There is a $7 \%$ success rate attached to this method. Yet this is a far cry to the $93 \%$ unemployed using just this method for job-hunting.

(5) Going to private agencies or search firm. This method also has a $5-24 \%$ success rate.

On the other hand, the job search strategies known to have high success possibilities for job hunting according to Nelson (1999) are: 
(1) Asking for job-leads from: family members, friends, people in the community, and staff at career centers. This method has 33\% success rate. That is for every 100 graduate that uses this method only 67 will not get a job.

(2) Knocking on the door of any employer, factory, or office that interest you, whether they are known or not. This method has $47 \%$ success rate. Meaning 53 graduates out of a 100 that use this job-search method will not have a job.

(3) By yourself using the phone book's yellow pages to identify subjects or fields of interest to you in the town or city where you are.

(4) In a group with other job-hunters, using the phone book's yellow pages to identity subjects or fields of interest to you in the town or city where you are, and then calling up the employers listed in that field, to ask if they hiring for the type of position you can do, and do well. This method has an $84 \%$ success rate.

(5) The creative approach to job-search. This method has $86 \%$ success rate. That is, out of every 100 graduate that uses this search method only 14 will not get the job if they use only this search method.

Nelson (1999) stated that the creative approach to job-search uses three vital guidelines for success as follows:

You must decide just exactly what you have to offer to the world. This involves identifying for yourself and others what your favorites or transferable skills are.

You must decide where you want to use your skills. This involves identifying your favorite subjects or field of interest, as well as your geographical preference.

You must go after the organization that interests you the most, whether or not they are known to have a vacancy. To go after these organizations implies using your contacts to get an appointment there.

The importance of acquisition of job search-skills can hardly be overemphasized. As Dabalen, Oni and Adikola (2000) observed, successful job search that will benefit an individual for life is a learned skill that a graduate must study, practice and master thoroughly. Factors militating against job search skills have also been given attention by scholars. The Nigeria education system according to Borishade (2001) tends to produce more of those who lack job skills for employment, than those the economy requires to be vibrant. According to him, the education system has been more quantitative without any qualitative dimension to it. Qualitative aspect according to Coombs (1969) cited in Hogan (2005) should be viewed as a living, moving thing whose goodness resides not only in its relevance and fitness to the changing needs of the particular graduate.

Matters arising from a recent brainstorming session by stakeholders in the education sector in Nigeria show that a number of factors are responsibly for lack of job-search skills in the Nigerian university graduate. These include:

(1) Deficiency in English and communication skills both linked with deficiency in primary and secondary education.

(2) Deficiency in technical skills.

(3) Lack of conceptual analytical skill.

(4) Lack of management skills in terms of human and material organizational skills.

These deficiencies according to the Development Policy Centre (1999) are attributable to factors such as decaying infrastructure facilities in the universities and lack of effective linkage between universities and industries in undergraduate training, and in research and development. Okebukola (2001) added the factor of poor academic staff conditions leading to brain drain and inability to recruit and retain high caliber academic staff.

\section{METHODS}

This is to a large extent a descriptive study relying on library research for secondary data and the questionnaire for primary data. The study used data got from structured questionnaires which were distributed to respondents selected for the study. The purposive sampling technique was adopted which enabled the researcher select the total number of 500 graduates (all serving members of the National Youth Service Corps, NYSC) with ease. NYSC is a programme established by the Federal Government of Nigeria in 1973 through which first degree graduates of not more than 30 years of age serve the nation for one year before qualifying for employment in government establishments. The population of study consisted of all Batch A and Batch B youth corps members serving in Cross River State in 2006.

The research instrument, the questionnaire, was administered on the respondents by two research assistants trained by the author for the purpose. The questionnaires were administered on Youth Corps members of Batch A and Batch B of 2006 as 
they trooped into Calabar after their orientation. The research assistants were able to collect most of questionnaires on the spot while the remaining few were collected at the contact addresses, usually a cyber cafe know to both of them.

The statistical tool of analysis for this study is simple percentages. It was used in analyzing respondents' responses to items in the questionnaire. Finding a decent job often depends on what search method one is using. The respondents in this study were therefore asked about their knowledge and use of the following job search methods already identified by scholars (Nelson 1999; Richard, 1999):

(1) Using the internet.

(2) Mailing out resumes to employer at random.

(3) Answering ads in professional or trade journal.

(4) Answering local newspaper ads.

(5) Going to private employment agencies

(6) Asking for job-leads.

(7) Knocking on the door of any employer, factory, or office that interest you, whether they are known to have a vacancy or not.

(8) By yourself, using the phone book's yellow pages.

(9) In a group with other job hunters.

(10) The creative approach to job-hunting or career-change.

This study is based on the following hypotheses:

(i) Graduates from tertiary institutions in Nigeria do not have problem hunting for job through the Internet.

(ii) There is no relationship between skill acquisition and successful job-hunting.

(iii) There is no significant relationship between academic background and ability to hunt for jobs on the Internet.

\section{RESULTS AND DISCUSSION}

\section{a. Sample characteristics}

Males were more heavily represented than females. Two hundred and thirty four youth corps members representing $56.8 \%$ were males while 216 representing $43.2 \%$ were females. Those aged 19 - 22 years are 125 in number constituting $25.0 \%$, while 194 youths representing $38.8 \%$ were between the ages of $23-26$, while those $27-30$ years were 181 in number and made up $36.2 \%$.

On the whole, 28 of the respondents constituting $5.6 \%$ come from very poor family background with monthly income of less than A5000. Again, 410 respondents representing $82 \%$ come from relatively rich families and have an average standard of living while 62 respondents representing $12.4 \%$ have a wealthy family background with high standard of living.

Eighty per cent of the respondents have university degree while the remaining 20 per cent have higher national diploma (HND). Generally, the respondents cut across various disciplines with those from humanities and social sciences background being more in the sample (Table1).

\section{b. Awareness of job search options}

Awareness of diverse job-hunting skills is widely spread among the respondents. Over $20 \%$ use the Internet in addition to the conventional media while another $40 \%$ who use friends or prominent family members have not applied through the Internet even though they are aware of it as a medium. However, while the Internet is gaining currency as a medium, some Youth Corpers expressed scepticism about it more than any other medium of job search due to the wide prevalence of scams and fraudsters. (Table 2).

\section{c. Various experiences of using the Internet}

At the time of this study, most of the over 20 per cent respondents who use the Internet have used two popular search engines namely, Google and Yahoo, to look for jobs in the Internet while a few others have not. They were asked to list the kind of problems encountered while hunting for job through the Internet. And their responses are similar were summarized here (see Table 3).

All those who have applied through the Internet encountered various difficulties such as not able to find the server; slowness of the server; not getting a reply or acknowledgement from the corporate organizations applied to; and inability to find job within Nigeria. Majority complained about stringent requirement. (Table 3 ).

\section{d. Skill acquisition and curriculum review}

While the bulk of the respondents 460, representing 92 per cent said their discipline or academic background does not hinder them from using the Internet, they were of the view that skill acquisition is paramount for successful job hunting and that the Nigerian education system need urgent overhaul in its curriculum to include various skills necessary for development. (Tables 4, 5 and 6)

Generally, the findings show that graduates of Nigerian tertiary institutions are increasingly using the Internet for job hunting in spite of the catalogue of problems they encounter. Thus, the null hypotheses that graduates of 
Nigerian tertiary institutions do not have problem hunting for job through the Internet and that there is no relationship between skill acquisition and successful job hunting are rejected in view of the findings to the contrary. On the other hand, the null hypothesis that there is no significant relationship between academic background and ability to hunt for jobs on the Internet is accepted as the respondents' responses supported it.

\section{CONCLUSION AND RECOMMENDATIONS}

From the foregoing, we can conclude that the Internet is gaining popularity as a medium for job hunting by Nigerian graduates even though it has minimal success rate. In Nigeria unlike the developed countries, peculiar problems such as power outage, slowness of server, and unavailability of job postings on the website, are encountered by job hunters. Also, the traditional media such as local newspaper ads, working-in to a corporate organization of interest, and contact through friends and family members are still very commonly used by graduates. Again, there is still high level of graduate unemployment in Nigeria. From the findings of this study, the author recommends as follows:

1. Internet service providers and cyber café owners in Nigeria should improve upon their services to the public.

2. Infrastructure such as steady power supply and enhanced communication network should be put in place by the Federal Government to improve the efficiency of cyber cafés.

3. Federal, state, and local governments as well as non-governmental corporate organizations should place their vacancy and jobs on the Internet for graduates to access.

4. There is need for thorough review of the curricula of Nigerian education system to include entrepreneurial skill acquisition as a basic requirement in all tertiary institutions.

5. Government should fund tertiary education properly so that facilities for quality teaching will be available for teachers.

6. Graduates should endeavour to sharpen their job-search skills by using the pertinent options suggested by scholars cited in this paper.

7. Lastly, Public-private partnership in information technology (IT) such as the one entered into by the Federal Government of Nigeria and Afri-HUB for tertiary institutions should be fortefied to equip future graduates with sound information and communication technology (ICT) background.

\section{REFERENCES}

Borishade, A., 2001. "Restructuring the educational system as a long-term solution to the unemployment problem in Nigeria", the Central Bank Billon, October/December.

Dabalen, A., Oni, B. and Adikola, O., 2000. Labor market prospects of University Graduates in Nigeria. Washington, D. C.: The World Bank.

Development Policy Centre, 1999. Nigeria the challenges of job creation: Policy Brief. Ibadan: DPC.

Duru, E. J. C., 1999. Oil Multinationals and the Niger Delta Crises: Issues and Perspectives. Owerri: African Scholars Publishing.

Hogan, N. U., 2005. University Graduates and Job Search: An Assessment of Job Search Strategies among NYSC Members in Cross River State (unpublished Degree Project submitted to the University of Calabar).

NDE, 2000. "Promoting support for Graduates employment", Abuja: National Directorate of Employment, PRS.

NDE, 2001. "Establishment of Graduates selfemployment index" Abuja: National Directorate of Employment, PRS Department.

Nwagbara, E. N., 2007. "Poverty, unemployment, insecurity, crime and violence in Nigeria: A somber reflection on neglected issues in sustainable development" International Journal of Development and Management Review, 1, 1, $17-27$, April..

Okebukola, P., 2001. "Re-designing University curricula as a long-term" Bank Bullion October/December 2001.

Richard, N., 1999. What color is your parachute? California: Fed speed Press. 
Robert, H., 1983. The Robert Halfway to get hired in Today's job market: New York: Bank Books.

Steven, M. and Michille, H., 1992. "Job search methods and results: tracking the unemployment 1991". Monthly Labor Review, December.

UNDP, 2004. Human Development Report, Cultural Liberty in Today's Diverse World. New York: United Nations Development Programme.

\section{APPENDIX}

Table 1: Shows distribution of sample characteristics

\begin{tabular}{|l|l|l|}
\hline Sex & No. of respondents & Percentage (\%) \\
\hline Male & 234 & 56.8 \\
Female & 216 & 43.2 \\
Total & $\mathbf{5 0 0}$ & $\mathbf{1 0 0 . 0}$ \\
\hline Age & & \\
$19-22$ & 125 & 25.0 \\
$23-26$ & 194 & 38.8 \\
$27-30$ & 18 & 36.2 \\
Total & $\mathbf{5 0 0}$ & $\mathbf{1 0 0 . 0}$ \\
\hline Type of degree & & \\
B.Sc & 400 & 80.0 \\
HND & 100 & 20.0 \\
Total & $\mathbf{5 0 0}$ & $\mathbf{1 0 0 . 0}$ \\
\hline Monthly in come & & \\
>AN,000 & 28 & 5.6 \\
<A10,000 & 410 & 82.0 \\
<A20,000 & 62 & 12.4 \\
Total & $\mathbf{5 0 0}$ & $\mathbf{1 0 0 . 0}$ \\
\hline Academic Background & & \\
Humanity/Arts & 120 & 24.0 \\
Social Science & 180 & 36.0 \\
Science & 60 & 12.0 \\
Education & 100 & 20.0 \\
Medical Science & 40 & 8.0 \\
Total & $\mathbf{5 0 0}$ & $\mathbf{1 0 0 . 0}$ \\
\hline
\end{tabular}

Table 2: Which job search strategy do you think is the best?

\begin{tabular}{|l|c|c|}
\hline \multicolumn{1}{|c|}{ Responses } & No. of respondents & Percentage (\%) \\
\hline Internet & 120 & 24.0 \\
Friends/family & 200 & 40.0 \\
Direct approach & 80 & 16.0 \\
Newspaper \& journals & 50 & 10.0 \\
Creative approach & 50 & 10.0 \\
\hline Total & $\mathbf{5 0 0}$ & $\mathbf{1 0 0 . 0 0}$ \\
& & \\
\hline
\end{tabular}

Source: Fieldwork by the author, 2006. 
Table 3: Various types of problems encountered by respondents using the Internet

\begin{tabular}{|l|l|}
\hline S/N & \multicolumn{1}{|c|}{$\quad$ Itemized problems } \\
\hline 1 & Cannot find server \\
2 & This page cannot be opened \\
3 & Power outage \\
4 & Slowness of the server \\
5 & Much cost in time and money \\
6 & Unavailability of desired jobs \\
7 & Few ads on Nigerian jobs \\
8 & No response after submission of application/resume \\
& \\
\hline
\end{tabular}

Source: Fieldwork by the author, 2006.

Table 4: Do you think skill acquisition can enhance job-hunting?

\begin{tabular}{|c|c|c|}
\hline Responses & No. of respondents & Percentage (\%) \\
\hline Yes & 455 & 91.0 \\
No & 45 & 9.0 \\
\hline Total & $\mathbf{5 0 0}$ & $\mathbf{1 0 0 . 0 0}$ \\
& & \\
\hline
\end{tabular}

Source: Fieldwork by the author, 2006.

Table 5: Do you think your academic background influence your ability to use the Internet?

\begin{tabular}{|c|c|c|}
\hline Responses & No. of respondents & Percentage (\%) \\
\hline Yes & 40 & 8.0 \\
No & 460 & 92.0 \\
\hline Total & $\mathbf{5 0 0}$ & $\mathbf{1 0 0 . 0 0}$ \\
\hline
\end{tabular}

Source: Fieldwork by the author, 2006.

Table 6: Do you think the curriculum of the Nigerian University system is currently impacting skills on the university graduates?

\begin{tabular}{|c|c|c|}
\hline Responses & No. of respondents & Percentage (\%) \\
\hline Yes & 88 & 17.6 \\
No & 412 & 82.4 \\
\hline Total & $\mathbf{5 0 0}$ & $\mathbf{1 0 0 . 0 0}$ \\
& & \\
\hline
\end{tabular}

Source: Fieldwork by the author, 2006. 